\title{
Kuzuların Gelişimi Üzerine Koyunların Doğum Dönemindeki Vücut Kondisyonu ve Canlı Ağırlığın Etkisi
}

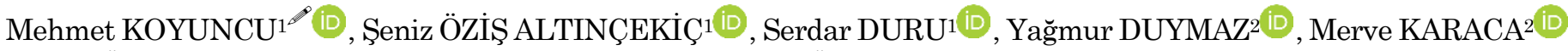 \\ ${ }^{1}$ Uludağ Üniversitesi Ziraat Fakültesi Zootekni Bölümü, Bursa, ${ }^{2}$ Uludağ Üniversitesi Fen Bilimleri Enstitüsü Zootekni Ana Bilim Dalı, Bursa \\ $\square$ : koyuncu@uludag.edu.tr
}

\begin{abstract}
ÖZET
$\mathrm{Bu}$ araştırma, 3-4 yaşlarındaki 115 baş Kıvırcık koyunda, doğum dönemindeki vücut kondisyon skoru (VKS) ve canlı ağırlığın kuzuların doğum ve sütten kesim ağırlığına etkilerini belirlemek için yürütülmüştür. Koyunlarda VKS doğumu takip eden gün içinde, bel bölgesinde omurların üzerindeki ve çevresindeki kas ve yağ birikiminin palpasyonu ile 1-5 aralığında puanlanarak yapılmıştır. Veriler VKS ve canlı ağırlığı içeren bir model ve üretim özelliklerini etkileyen diğer faktörler kullanılarak analiz edilmiştir. Doğum dönemindeki koyunların VKS, canlı ağırlığı, kuzuların doğum ağırlığı, sütten kesim ağırlığı ve günlük canlı ağırlık artışı (doğumdan sütten kesime kadarki dönemde) değerlerinin ortalaması sırasıyla $2.9,57.1 \mathrm{~kg}, 4.5 \mathrm{~kg}, 23.6 \mathrm{~kg}$ ve $0.249 \mathrm{~kg}$ olarak saptanmıştır. Ele alınan özelliklerden VKS ile koyunların canlı ağırlığı, kuzu doğum ağırlığı ve günlük canlı ağırlık artışı arasında pozitif önemli korelasyonlar 0.440, 0.301 ve 0.219 bulunmuştur $(\mathrm{P}<0.01 ; \mathrm{P}<0.05)$. VKS'nin kuzularda sadece doğum ağırlığı üzerine önemli $(\mathrm{P}<0.01)$ bir etkiye sahip olduğu saptanmıştır. Sonuç olarak Kıvırcık koyun sürüsünde gebelik döneminin sonunda VKS'nin 3.0-3.5 olması ve aynı zamanda gebelik boyunca da bu değerin altına düşmemesinin önemi ortaya konmuştur.
\end{abstract}

\section{The Effect of Live Weight and Body Condition Score of Ewe on Growth of Lamb at Lambing Period}

\section{ABSTRACT}

This study was carried out to determine the effect of birth and weaning weight of lamb of ewe body condition score (BCS) and ewe birth weight at lambing period on 115 Kivircik ewes at the 3-4 years of age. BCS was assessed 1 day after lambing, based on a scale of 1-5, by palpation of muscling and fat deposits over and around the vertebrae in the loin region. The data set was analyzed using a model that included body condition score, live weight of ewes, as well as other factors that affected productive traits. The results showed that the overall mean ewe BCS at lambing, ewe live weight, birth weight, weaning weight and daily live weight gain (from birth to weaning) were $2.9,57.1 \mathrm{~kg}, 4.5 \mathrm{~kg}, 23.6 \mathrm{~kg}$ and $0.249 \mathrm{~kg}$, respectively. As a result of the analyses, the relationship between body condition score and ewe lambing weight, birth weight and daily live weight gain of lamb were found to be $0.440,0.301$, and 0.219 , respectively $(\mathrm{P}<0.01 ; \mathrm{P}>0.05)$. The effect of ewe BCS was only significant $(\mathrm{P}<0.01)$ effect on lamb birth weight. According to the results, BCS at the end of the gestation period should be at least 3.0-3.5 and also this condition should be maintained during the period of gestation in Kivircik ewes.
DOI:10.18016/ksutarimdoga.vi.420321

\section{Makale Tarihçesi}

Geliş Tarihi: 02.05.2018

Kabul Tarihi : 25.06.2018

Anahtar Kelimeler
Kıvırcık,
vücut kondisyon skoru,
kuzulama ağırlı̆ğ,
büyüme özellikleri

Araştırma Makalesi

\section{Article History}

Received : 02.05.2018

Accepted : 25.06.2018

\author{
Keywords \\ Kivircik, \\ body condition score, \\ lambing weight, \\ growth traits
}

Research Article

To cite: Koyuncu M, Öziş Altınçekiç Ş, Duru S, Duymaz Y, Karaca M. 2018. Kuzuların Gelişimi Üzerine Koyunların Doğum Dönemindeki Vücut Kondisyonu ve Canlı Ağırlı̆̆ın Etkisi. KSÜ Tar Doğa Derg 21(6) : 916-925, DOI : 10.18016/ksutarimdoga.vi.420321 


\section{GİRIŞ}

Üretim döngüsünün farklı aşamaları için (üreme, gebelik, laktasyon) koyunların kondisyonlarının (çok zayıf, çok yağlı veya ideal) bilinmesi önemlidir. VKS, bir hayvanın kas ve yağ gelişiminin sübjektif olarak tahminidir ve son kaburga kısmındaki derinliğin veya hayvan vücudundaki yağ oranının ölçümü ile ilişkilidir (Russel ve ark., 1969; Sanson ve ark., 1993). VKS aynı zamanda sürünün beslenme durumunu değerlendirmenin öznel bir yolu olup, yetiştiricilerin sürülerindeki verimliliği artırmaları için potansiyel bir gösterge olarak da kullanılabilir (Sejian ve ark., 2010). Sürüdeki koyunların üretim döngüsünün her aşaması için optimum bir VKS vardır. Özellikle üreme verimliliği ile VKS arasında pozitif korelasyon olduğunu bildiren birçok çalışma bulunmaktadır (Atti ve ark., 2001; Abdel-Mageed, 2009; Sejian ve ark., 2010; Yllmaz ve ark., 2011).

VKS ve kullanımı, ekstansif yetiştirme koşullarının baskın olduğu koyun yetiştiriciliğinde belirli fizyolojik dönemlerde istenen performansı elde etmek açısından da değerlendirilebilir. Lopez ve ark. (1995), koyunlarda vücut kondisyonundaki değişimin döl ve süt verimine etkilerini inceledikleri çalışmada, yıl boyunca vücut rezervlerindeki değişimlerin üreme performansı üzerine olumlu bir etki yaptığını fakat süt verimi üzerine etkisinin olmadığını saptamışlardır. Vücut enerji rezervleri (yağ ve kas), üreme performansı ve karkas kalitesinin önemli bir belirleyicisidir. Hayvanlar pozitif enerji dengesine sahip olduğunda fazla enerji vücutta yă̆ olarak depolanır. Negatif enerji dengesi durumunda ise vücuttaki yağ depoları kullanılır (Samardzija ve ark., 2013). Hayvan vücudundaki yağ dokusu rezervlerinin bilinmesi sağlıklı ve verimli bir sürünün elde tutulması açısından son derece önemlidir.

Gebelik, kuzulama ve sütten kesim döneminde koyunun vücut kapasitesinin profili, üreme performansının bir göstergesi olarak verimliliği arttırma noktasında işletmede sürü yönetimine yönelik kararlar alınırken de bir araç olarak kullanılabilir. Canlı ağırlık, bir hayvanın vücut büyüklüğü kadar vücut kondisyonuna da bağlı olup, VKS bir koyunda enerji rezervlerinin belirlenmesinde canlı ağırlıktan daha fazla belirleyici olabilmektedir. $\mathrm{Bu}$ durum, Sanson ve ark. (1993) tarafindan ergin koyunlarda ortaya konulurken, Borg ve ark. (2009) ise canlı ağırlık ve VKS ile gebelik esnasındaki canlı ağırlık gelişiminin kuzulama ve sütten kesim sonuçları arasında bir ilişki olduğunu göstermiştir. Ayrıca, laktasyon sırasında canlı ağırlık kaybeden ve sonrasında çiftleşme ve gebelik döneminde canlı ağırlık artışı ile durumu telafi eden koyunların, kuzu büyütme ve analık kabiliyeti bakımından yüksek genetik değerlere sahip olduğu belirlenmiştir. Diğer taraftan çiftleşme sırasında koyunun vücut ağırlığının sonraki yavru verimini (Gordon, 1997) ve genel anlamda koyunun verimliliğini etkilediği de ortaya konmuştur (Vatankhah ve ark., 2012).

Çiftleşme dönemi öncesi ve sonrası VKS ve canlı ağırlığın (statik etkiler) ve dönem içinde VKS ve canlı ağırlıkta ortaya çıkan değişimlerin (dinamik etkiler), farklı yetiştirme sistemlerindeki irkların üreme performansı üzerine etkisine yönelik de birçok çalışma yapılmıştır. Araştırmacıların çoğu VKS ve canlı ağırlıktaki varyasyonun koyunlarda üreme performansı üzerinde önemli bir etkiye sahip olduğunu, beslenme, fizyolojik koşullar ve üreme arasındaki etkileşimlerin önemini ortaya koymuşlardır. $\mathrm{Bu}$ çalışmalarda VKS'nin üreme performansina (Yılmaz ve ark., 2011), kolostrum üretimine (Jalilian ve Moeini, 2013), kuzuların hayatta kalma ve büyüme oranlarına doğrudan etkileri saptanmıştır (Sarı ve ark., 2013; CornerThomas ve ark., 2015). Kaliteli kolostrum üretimi için gebeliğin sonu ve kuzulama döneminde koyunların iyi vücut kondisyonunda olmalarının gerekliliği tartışlmaz bir gerçektir.

$\mathrm{Bu}$ araştırmada Kıvırcık koyunlarında doğum dönemindeki VKS ve canlı ağırlığın (CA) kuzuların doğum ağırlığ̣ (DA) ve sütten kesim ağırlığ bu dönemler arasındaki günlük canlı ağırlık artışına (GCAA) etkileri belirlenmeye çalışılmıştır.

\section{MATERYAL ve METOT}

\section{Hayvan Materyali}

$\mathrm{Bu}$ araştırmanın materyalini Uludağ Üniversitesi Ziraat Fakültesi Araştırma ve Uygulama Çiftliği'nde yetiştirilen daha önce doğum yapmış 3-4 yaşlı 115 baş Kıvırcık ırkı koyun ve bunlardan doğan 128 baş kuzu oluşturmuştur. Aralık-Ocak ayları içinde doğum yapan koyunların doğumu takip eden 24 saat içinde CA tartılmış ve doğumdaki VKS belirlenmiştir. Aynı zamanda doğan kuzular bir saat içinde tartılarak DA belirlenmiş ve kulak numaraları takılmıştır. Doğum yapan koyunlar ve kuzuları diğer koyunlardan ayrı bir bölmede tutulmuş ve iki haftanın sonunda kuzulara alıştırma yemlemesi (creep feeding) uygulamasına geçilmiştir. Kuzular için ağıl içinde ayrılan bu alanda daima temiz su ve kaliteli kaba yem ve kuzu büyütme yemi bulundurulmuştur. Kuzular isteğe bağlı olarak alıştırma yemlemesi alanına veya analarının yanına rahatlıkla geçebilmişlerdir. Mevsim koşullarından dolayı koyunlar bu dönemde ağıl içinde tutulmuşlardır. Koyunlara kaba yem olarak kuru ot ve yonca $(1.5 \mathrm{~kg} / \mathrm{baş})$, yoğun yem olarak $\% 57.5$ buğday, $\% 15$ misır, \%25 ayçiçeği tohumu küspesi, \%1.3 mermer tozu, \%1 tuz ve \%0.20 vitamin ve mineral içeren karışım (400 g/baş) sabah ve akşam olmak üzere günde $2 \mathrm{kez}$ ve her gün aynı saatte verilmiştir. Hayvanların önünde sürekli olarak temiz su ve mineral gereksinimlerinin karşılanması için yalama taşı bulundurulmuştur. Kuzular farklı sürelerde ve yaklaşık 2.5-3 aylık yaşta sütten kesilmiş ve bu 
dönemde SKA belirlenmiştir. Bu nedenle SKA'nın değerlendirildiği modele sütten kesim yaşı (SKY) kovaryet olarak dâhil edilmiştir. Kuzularda DA, SKA ve her bir kuzunun SKY bilindiğinden, doğum-sütten kesim arası GCAA hesaplanmıştır. Araştırmada ikiz doğan 7 baş kuzu, doğumu takip eden ilk bir ay içinde ölmüştür bu nedenle bunların SKY ve SKA verisi eksiktir.

\section{Vücut kondisyonunun belirlenmesi}

Bel bölgesindeki kas ve deri altı yağ depolarının subjektif olarak değerlendirilmesine dayanan VKS, koyunlarda zamanla beslenme durumundaki değişikliklerin değerlendirilmesi için kullanılan bir göstergedir (Khan, 1993). VKS uygulaması için 1 den 5'e kadar yapılacak puanlamada, puanlama aralığ 0.5 olarak kabul edilmiştir. Koyunlara bel bölgesinin çevresindeki kas ve yağ birikimine bağlı olarak 5 (obez) ve 1 (zaylf) puan verilmiştir (Thompson ve Meyer, 2006). Uygulama Russel ve ark. (1969), ile Thompson ve Meyer (1994), tarafindan belirtilen esaslar çerçevesinde yapılmıştır. Bu sistemde subjektif olarak puanlama, bel bölgesinden son kaburga kemiğinin hemen arkasında yer alan omurun etrafı ve üzerindeki kas ve yağ dokusuna deri üzerinden dokunarak ve parmak uçlarının anılan bölgede gezdirilmesi (handling) ile yapılmaktadır. Bu yöntemle parmak uçları ile son kaburganın hemen arkasından bel kemiği ve kısa kaburgaların ucuyla omurga hissedilmeye çalışılır (Şekil 1 ve 2). Araştırmada skorlama, koyunlarda VKS'nin DA ve SKA'ya etkisini belirlemek için doğumu takip eden 24 saat içinde yapılmıştır. VKS için gruplar oluştururken 1.5 ve 2 puan alan koyunlar veri azlığı nedeniyle 2.5 grubunda, 4 puan alanlar da 3.5 grubunda birleştirilmiştir.
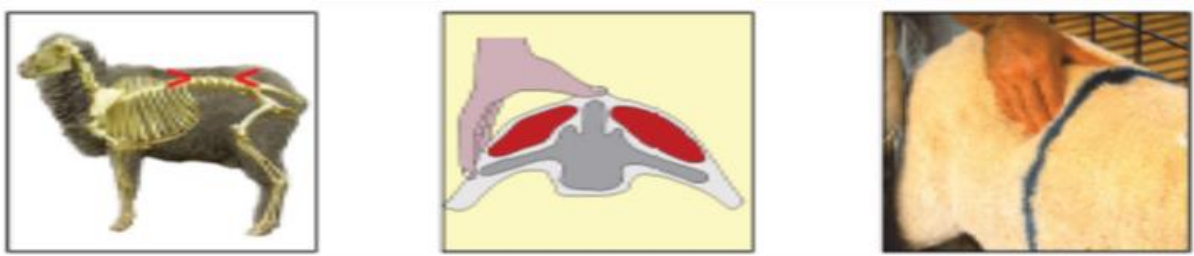

Şekil 1. Koyunlarda vücut kondisyon puanlaması için değerlendirme noktaları (Anonim, 2013)
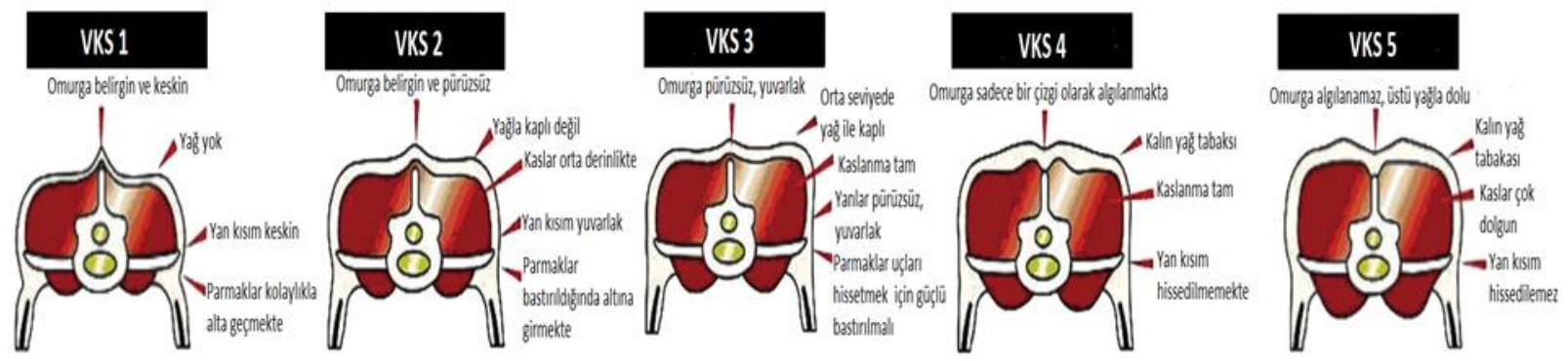

Şekil 2. Vücut kondisyon skoru değerlendirilme kriterleri (Anonim, 2013)

\section{İstatistik analizler}

Araştırmada incelenen özelliklere ait verinin normal dağılıma uygunluğu Anderson-Darling testi ile kontrol edilmiş ve normal dağıldığı görülmüştür. Bu nedenle verilere herhangi bir dönüşüm uygulanmamıştır. Büyüme özelliklerine etkili faktörleri belirlemek için varyans analizi ve grupların karşılaştırılmasında LSD çoklu karşılaştırma testi yapılmıştır. Analizler için Minitab 17.0 programinin GLM prosedürü kullanılmıştır (Minitab, 2010). Ayrıca değerlendirilen özellikler arası korelasyonlar da hesaplanmıştır.

DA ve GCAA için kullanılan doğrusal modellerde sürekli varyasyon gösteren koyunların ağırlıkları kesikli hale getirilmiştir. Bunun için ana ağırlığı grupları; hafif $<50 \mathrm{~kg}$, orta $\leq 50-<60 \mathrm{~kg}$ ve ağır $\geq 60 \mathrm{~kg}$ olarak belirlenmiştir. Kullanılan model;

$\mathrm{Y}_{\mathrm{ijklm}}=\mu+\mathrm{C}_{\mathrm{i}}+\mathrm{DT}_{\mathrm{j}}+\mathrm{VKS}_{\mathrm{k}}+\mathrm{CA}_{\mathrm{l}}+\mathrm{e}_{\mathrm{ijklm}}$
SKA için kullanılan model ise aşağıdaki şekildedir.

$\mathrm{Y}_{\mathrm{ijklm}}=\mu+\mathrm{C}_{\mathrm{i}}+\mathrm{DT}_{\mathrm{j}}+\mathrm{VKS}_{\mathrm{k}}+\mathrm{CA}_{\mathrm{l}}+\mathrm{b}_{1} \mathrm{X}_{\mathrm{ijklm}}+\mathrm{b}_{2} \mathrm{Z}_{\mathrm{ijklm}}+$ $\mathrm{e}_{\mathrm{ijk} k \mathrm{~m}}$

Modellerde kullanılan sembollerin anlamları aşağıdaki gibidir.

$\mathrm{Y}_{\mathrm{ijklm}}: i$. cinsiyette $j$. doğum tipinde $k$. VKS'de $l$. ağırlık grubundaki anadan doğan $m$ kuzusunun doğum veya sütten kesim ağırlığg, $\mu$ : populasyonun beklenen ortalaması, $\mathrm{C}_{\mathrm{i}}: i$. cinsiyetin etkisi (erkek, dişi), $\mathrm{DT}_{\mathrm{j}}: j$. doğum tipinin etkisi (tek, ikiz), $\mathrm{VKS}_{\mathrm{k}}: k$. vücut kondisyon skorunun etkisi $(2.5,3.0,3.5), \mathrm{CA}_{1}: 1$. ana ağırlık grubunun etkisi, $b_{1}$ : sütten kesim ağırlığının doğum ağırlığına kısmi regresyon katsayısı, $b_{2}:$ sütten kesim ağırlığının sütten kesim yaşına kısmi regresyon katsayısı, $\mathrm{X}_{\mathrm{ijk} \mathrm{km}}$ : $i$. cinsiyette $j$. doğum tipinde k. VKS'de l. ağırlık grubundaki anadan doğan $m$ kuzusunun doğum ağırlığı, $Z_{\mathrm{ijklm}}: i$. cinsiyette $j$. doğum tipinde $k$. 
VKS'de 1 . ağırlıkta anadan doğan $m$ kuzusunun sütten kesim yaşı, eijk: ortalaması 0 standart sapması 1 olan normal dağılım gösteren hata etkisi.

\section{BULGULAR ve TARTIŞMA}

Araştırmada değerlendirilen özellikler için tanımlayıcı istatistikler Çizelge 1'de verilmiştir. CA, VKS, DA, SKA, SKY ve GCAA için ortalamalar sırasıyla $57.1 \mathrm{~kg}$, $2.9,4.5 \mathrm{~kg}, 23.6 \mathrm{~kg}, 76.5$ gün ve $0.249 \mathrm{~kg}$ olarak bulunmuştur. Kıvırcık koyunlarının doğum dönemi canlı ağırlıkları 40.6-78.5 kg, DA 2.2-6.4 kg, SKY 6393 gün ve SKA 12.6-36.1 kg arasında değişmiştir. CA'da geniş bir varyasyonun olduğu görülmektedir. Aynı çizelgede kuzuların DA ve SKA etkileyen faktörlere göre düzeltilmiş değerlerden hesaplanan en küçük ve en büyük değerler ile standart sapmaları verilmiştir. Beklendiği gibi düzeltilmiş değerlerde varyasyon ve dolayısıyla standart sapma azalmıştır. Araştırmada kullanılan koyunlar 3-4 yaşlı olup, doğru bir ayırım yapılamayacağından dolayı yaş değerlendirmeye alınmamıştır. Bu konuda yapılan çalışmalarda da koyunun yaşının kuzunun tüm gelişme dönemi boyunca canlı ağırlığa etkisinin olmadığı, ana yaşının doğum ağırlığı ve farklı yaşlardaki kuzuların canlı ağırlı̆̆ına etkisinin önemsiz olduğunu ifade eden çalışmalar bulunmaktadır (Aliyari ve ark., 2012; Aktaş ve Doğan, 2014)

Çizelge 1. Koyunların CA, VKS ve kuzularının büyüme özelliklerine ait değerler

\begin{tabular}{llllll}
\hline Özellikler & $\mathbf{N}$ & $\overline{\boldsymbol{X}} \pm \boldsymbol{S}_{\overline{\mathbf{X}}}$ & $\boldsymbol{\sigma}$ & Minimum & Maksimum \\
\hline CA (kg) & 115 & $57.1 \pm 0.76$ & 8.2 & 40.6 & 78.5 \\
VKS & 115 & $2.9 \pm 0.04$ & 0.44 & 1.5 & 4.0 \\
DA (kg) & 128 & $4.5 \pm 0.15$ & 0.8 & 2.2 & 6.4 \\
DA_EKK (kg) & 128 & $4.5 \pm 0.07$ & 0.4 & 3.3 & 5.2 \\
SKA (kg) & 121 & $23.6 \pm 0.47$ & 4.6 & 12.6 & 36.3 \\
SKA_EKK (kg) & 121 & $23.6 \pm 0.31$ & 3.4 & 14.7 & 33.9 \\
SKY (gün) & 121 & $76.5 \pm 0.83$ & 9.0 & 63 & 93 \\
GCAA (kg) & 121 & $0.249 \pm 0.004$ & 0.049 & 0.139 & 0.419 \\
\hline
\end{tabular}

Kuzuların DA, SKA ve GCAA üzerine etkili faktörler, standart hataları ve önem düzeyleri Çizelge 2'de verilmiştir. Doğum tipi ve cinsiyetin DA, SKA ve GCAA üzerine etkileri önemlidir $(\mathrm{P}<0.01 ; \mathrm{P}<0.05)$. Tek doğmuş erkek kuzuların ikiz ve dişi kuzulardan daha iyi doğum ve büyüme özelliklerine sahip olduğu görülmektedir. Tek doğanların ikizlerden yaklaşık 1 $\mathrm{kg}$, erkeklerin de dişilerden $0.3 \mathrm{~kg}$ ağır doğdukları bulunmuştur. Buna paralel olarak sütten kesimde tek doğanlar ikizlerden $2.5 \mathrm{~kg}$, erkekler dişilerden $1.5 \mathrm{~kg}$ daha ağırdır. Bu durum ağır doğan kuzuların takip eden zaman diliminde başlanan creep feeding uygulamasına daha kısa sürede adapte olduklarını ve kaba ve yoğun yemlerden daha iyi yararlanabildiklerinin bir göstergesi olarak kabul edilebilir. Oransal olarak bakıldığında ikiz doğanlar tek doğanlardan doğumda $\% 20$, sütten kesimde $\% 11$, GCAA için \%13 daha düşük büyüme performansı göstermişlerdir. Dişiler erkeklerden doğumda \%7, sütten kesimde $\% 6$ ve GCAA için $\% 9$ daha dezavantajlıdırlar. $\mathrm{Bu}$ araştırma sonuçlarına benzer şekilde İdris ve ark. (2011) ve Aktaş ve Doğan (2014) erkek kuzuların doğumdan 120 güne kadar dişilerden daha ağır olduğunu bildirmişlerdir (sırasıyla $\mathrm{P}<0.05$, $\mathrm{P}<0.001)$. Sarı ve ark. (2013) ise cinsiyetin doğum ile 180 günlük yaş arasındaki kuzu canlı ağırlıkları üzerinde anlamlı bir etkisi olmadığını belirtmiştir. Kuzu cinsiyetinin farklı yaşlardaki canlı ağırlıklar üzerinde önemli bir etkisinin olmadığı, ancak erkek kuzuların 60-120 gün arasında dişi kuzulardan daha ağır olduğu ifade edilmektedir (Karakuş ve Atmaca,
2016). Bu araştırmada tekiz doğanların DA, SKA ve GCAA artışı ikizlere göre daha yüksektir. Bu sonuçlar Sarı ve ark. (2013) ile Karakaş ve Atmaca (2016)'nın doğum ağırlığının doğum tipinden anlamlı düzeyde $(\mathrm{P}<0.001) \quad$ etkilendiğini bildiren çalışmalarına benzerlik göstermektedir.

Bu çalışmada CA'nın kuzuların DA ve SKA'ya etkisi önemli bulunmamıştır. Ağır anaların kuzuları hafif anaların kuzularından doğumda ve sütten kesimde daha ağır olmalarına ve yaklaşık 15 g/gün daha hızlı GCAA sağlamalarına rağmen aradaki farklar istatistiki olarak önemli bulunmamıştır. $\mathrm{Bu}$ sonuç Corner-Thomas ve ark. (2014) tarafindan bulunan sonuçlara benzerdir. McCall ve ark. (1986), koyunlarda kuzulama öncesi canlı ağırlığın kuzu canlı ağırlık gelişimi üzerinde olumlu bir etkisi olduğunu, benzer şekilde gebeliğin son döneminde koyunların yüksek canlı ağırlığı ve kondisyon değerlerinin de kuzuların gelişimini olumlu yönde etkilediği bildirilmiştir (Gibb ve Treacher, 1980; Wilson ve ark., 1985; Hossamo ve ark., 1986).

Russel ve ark., (1981) ise çiftleşme dönemindeki koyunların canlı ağırlığının, gebelik döneminde, normalin altında bir beslenme seviyesinde tutulsalar bile tekiz kuzuların doğum ağırlığı üzerinde önemli bir etkiye sahip olduğunu, ikiz kuzuların doğum ağırlıklarının ise, önemli ölçüde olmamakla birlikte, çiftleşme sırasındaki kondisyon puanlarının artmasiyla artma eğiliminde olduğunu ifade etmektedirler. Koç katım dönemindeki canlı ağırlık ve kondisyon puanlarının kuzuların doğum ağırlığına ve 
ikiz kuzularda büyüme oranlarına belirgin bir etkisinin olduğu ortaya konmuştur (Kenyon ve ark., 2004). Wallace (2000) ve Wallace ve ark. (2008)'nın bulguları ise uzun süreli yanlış beslemenin koyunların yüksek canlı ağırlığa ulaşmalarına, bunun da daha hafif kuzu DA ile ilişkili olduğu yönündedir. Benzer şekilde, Smeaton ve ark. (1999), çiftleşme dönemi canlı ağırlıklarının yaklaşık $5 \mathrm{~kg}$ ile farklılık göstermesi halinde, koyunların canlı ağırlığının kuzuların DA veya SKA'ya etkisinin olmadığını bildirmişlerdir. Schreurs ve ark. (2010), kuzu doğum ağırlığı ve sütten kesim ağırlı̆̆ı üzerine gebeliğin son dönemindeki canlı ağırlığın küçük bir pozitif etkisi olduğunu belirtmişlerdir. 7 aylık dönemde gebe kalan koyunların bu dönemdeki beslenmeleri gebeliğin son dönem canlı ağırlığını etkilediğini, bunun da kuzuların sütten kesim ağırlığı üzerinde olumlu bir etkiye sahip olduğu bildirilmiştir (Kenyon ve ark., 2008; Morris ve ark., 2005; Mulvaney ve ark., 2010). Bu da dişi kuzu veya tokluların canlı ağırlığının mümkün olduğunca yüksek olmasının doğuracakları kuzuların SKA'yı arttırmanın bir aracı olduğunu göstermektedir.

Çizelge 2. Kuzularda DA, SKA ve GCAA için hayvan sayısı (n), en küçük kareler ortalaması (kg) ve standart hatalar

\begin{tabular}{|c|c|c|c|c|c|}
\hline Faktör & $\begin{array}{l}\mathrm{DA} \\
\mathrm{n}\end{array}$ & $\bar{X} \pm S_{\bar{X}}$ & $\begin{array}{l}\text { SKA } \\
\text { n }\end{array}$ & $\bar{X} \pm S_{\bar{X}}$ & $\begin{array}{l}\text { GCAA } \\
\bar{X} \pm S_{\bar{X}}\end{array}$ \\
\hline D. Tipi & & $* *$ & & $* *$ & $* *$ \\
\hline Tek & 102 & $4.7 \pm 0.07^{\mathrm{a}}$ & 98 & $24.1 \pm 0.38^{\mathrm{a}}$ & $0.257 \pm 0.005^{\mathrm{a}}$ \\
\hline İkiz & 26 & $3.8 \pm 0.13^{\mathrm{b}}$ & 23 & $21.5 \pm 0.77^{b}$ & $0.210 \pm 0.0091^{b}$ \\
\hline Cinsiyet & & $* *$ & & * & * \\
\hline Erkek & 63 & $4.4 \pm 0.09 \mathrm{a}$ & 59 & $23.5 \pm 0.48^{\mathrm{a}}$ & $0.246 \pm 0.006^{\mathrm{a}}$ \\
\hline Dişi & 65 & $4.1 \pm 0.10^{\mathrm{b}}$ & 52 & $22.1 \pm 0.56^{\mathrm{b}}$ & $0.221 \pm 0.007^{\mathrm{b}}$ \\
\hline Ana Ă̆ır. & & ÖD & & ÖD & ÖD \\
\hline Hafif & 25 & $4.2 \pm 0.14$ & 21 & $22.9 \pm 0.84$ & $0.226 \pm 0.011$ \\
\hline Orta & 53 & $4.3 \pm 0.10$ & 52 & $22.4 \pm 0.54$ & $0.234 \pm 0.007$ \\
\hline Ağır & 50 & $4.4 \pm 0.10$ & 48 & $23.1 \pm 0.52$ & $0.240 \pm 0.0071$ \\
\hline VKS & & $* *$ & & ÖD & ÖD \\
\hline$\leq 2.5$ & 27 & $4.0 \pm 0.10^{\mathrm{b}}$ & 39 & $22.3 \pm 0.58$ & $0.225 \pm 0.007$ \\
\hline 3 & 60 & $4.3 \pm 0.10^{\mathrm{ab}}$ & 55 & $23.0 \pm 0.56$ & $0.235 \pm 0.007$ \\
\hline$\geq 3.5$ & 41 & $4.5 \pm 0.14^{\mathrm{a}}$ & 27 & $23.1 \pm 0.70$ & $0.240 \pm 0.009$ \\
\hline $\mathrm{b}_{1}$ & & & & $2.43^{* *}$ & \\
\hline $\mathrm{b}_{2}$ & & & & $0.326^{* *}$ & \\
\hline
\end{tabular}

$\mathrm{b}_{1}$ : DA'nın SKA üzerine, $\mathrm{b}_{2}$ : SKY'nin SKA üzerine regresyon katsayısı.

${ }^{* *} \mathrm{P}<0.01,{ }^{*} \mathrm{P}<0.05$

Hayvanların enerji durumunu veya beslenme refahını tahmin etmek amaciyla, canlı ağırlığa göre daha fazla tercih edilen VKS geliştirilmiştir (van Burgel ve ark., 2011). Koyunun canlı ağırlığı genellikle temel iskelet boyutu ve vücut kondisyonu olmak üzere iki bileşene sahiptir. Koyunlar arasında iskelet büyüklüğündeki değişiklik nedeniyle, vücut ağırlığı tek başına kondisyon derecesini gösterememektedir. Koyunun kondisyon skorunun üretkenlik (kuzu doğum ağırlığı ve koça verilen her 100 koyundan sütten kesimde elde edilen toplam kuzu ağırlığı gibi) üzerinde önemli bir etkisi bulunmaktadır.

Bu araştırmada kuzulama dönemi için bulunan ortalama VKS değeri (2.9) Sezenler ve ark. (2011) bulgusundan (3.3) düşüktür. Kuzu üretim sistemlerinde, toplam sütten kesilen kuzu sayısının ve ağırlığının kârlılık üzerinde önemli bir etkisi bulunmaktadır (Morel ve Kenyon, 2006; Young ve ark., 2010). Koyunlarm enerji dengesi, sütten kesilen kuzu sayısını ve ağırlığını etkileyen önemli bir faktördür (Scaramuzzi ve ark., 2006). Bu nedenle düşük VKS'li koyunların kuzularının, yüksek olanlara göre sütten kesim döneminde daha düşük bir performans göstermesi beklenebilir. Buna neden olan etkenlerin başında kondsiyonu düşük olan koyunların süt verimlerinin de düşük olabileceği ihtimali gelmektedir.

VKS’nin DA üzerine etkisi önemli $(\mathrm{P}<0.01)$ bulunmasına rağmen, SKA ve GCAA üzerine etkisi önemli değildir. Araştırmada, istatistiksel olarak anlamlı olmamakla birlikte, en yüksek VKS'ye sahip (3.5) koyunlardan doğan kuzuların, SKA ve GCAA'nın VKS 2.5 ve 3.0 olan koyunlardan doğan kuzulardan daha yüksek olduğu gözlenmiştir. Koyunların kondisyon değerlerinin kuzuların gelişimi üzerindeki olumlu etkisi MathiasDavis ve ark. (2013) ve Sarı ve ark. (2013) tarafindan da belirtilmektedir. VKS 3 olan Sanjabi koyunlarından doğan kuzularının DA'nın diğer gruplara göre daha yüksek olduğunu ve daha iyi bir üreme performansı gösterdiği belirtilmektedir (Jalilian ve ark., 2012; Jalilian ve Moeini, 2013). VKS 3.5 olan koyunlardan doğan ve sütten kesilen kuzuların aynı koşullardaki diğer koyunların kuzularına göre daha yüksek gelişim gösterdiği ifade edilmektedir (Rhind ve ark., 2001). Doğumda toplam kuzu ağırlığı ve koçaltı koyun başına düşen kuzu sayısı, 3.5 VKS koyunlarda artarken, 4 VKS'li koyunlarda azalmıştır (Vatankhah ve ark., 2012). $\mathrm{Bu}$ noktada 3.5 üstü kondisyona sahip koyunlarda toplam kuzu ağırlığı ve kuzu sayısındaki azalma eğilimi, daha yüksek olan yaşama ve verim payı 
gereksinimlerine atfedilebilir, çünkü VKS 4'ün üstünde olanlar, VKS 3-3.5 olan koyunlardan daha ağırdır. Bu noktada kuzulama dönemindeki koyunların kondisyon skoru ve buna uygun besleme programı kuzuların sütten kesime kadar gelişiminde önemli olduğunu belirten başka çalışmalar da bulunmaktadır (Khan, 1993; Sezenler ve ark., 2008; Al-Sabbagh, 2009; Mathias-Davis ve ark., 2013).

VKS'nin, kuzularin DA'yı etkilemediğini belirten çalışmalar da bulunmaktadır (Al-Sabbagh ve ark., 1995; Aliyari ve ark., 2012). Bu kapsamda değerlendirildiğinde, koyunların gebeliğin son dönemindeki VKS'nin kuzuların gelişimi üzerinde etkisinin olmadığını belirten çalışmalarda aşırı beslenen koyunlarin (Gibb ve Treacher, 1982), veya koyunlar içinde düşük kondisyon değerine sahip olanların mukayese edildiği görülmektedir (Litherland ve ark., 1999). Kenyon ve ark. (2004) çok yüksek vücut kondisyon değerlerinin olumsuz etkilerini ve gebeliğin son döneminde ortaya çıkan fazla canlı ağırlığın kuzu DA üzerinde olumsuz bir etkiye sahip olabileceğini ifade etmektedir.

Kondisyonun kuzuların SKA'yı etkilemediğini bildiren araştırma sonuçlarının yanı sıra, çok zayıf VKS'li koyunlardan doğan kuzuların daha düşük SKA'ya sahip olduğunu bildirenler de olmuştur (Al-Sabbagh ve ark., 1995; Kenyon ve ark., 2011; Sejian ve ark., 2009). Benzer şekilde bazı çalışmalarda anlamlı bir etki bulunurken (Jalilian ve Moeini, 2013; Corner-Thomas ve ark., 2015; Sejian ve ark., 2015), diğerlerinde hiçbir etkiye rastlanmamıştır (Aliyari ve ark., 2012; Kenyon ve ark., 2013; Corner-Thomas ve ark., 2015). Sonuçlar arasındaki farklılığa, değerlendirme koşulları, VKS zamanlaması, orta veya geç gebelik ve emzirme dönemindeki besleme koşullarının neden olabileceği unutulmamalıdır.

Kondisyon değerlendirmelerinin üreme performansına etkilerini ortaya koyan çalışmalarda da ekstansif koşullarda yetiştirilen Kıvırcık koyunlarında koç katımında yapılan değerlendirme sonucunda VKS'nin koyunların gebelik ve kuzulama oranına ile koçaltı koyun başına düşen kuzu sayısına etkisinin önemli $(\mathrm{P}<0.05)$ (Yılmaz ve ark., 2011) ve Tuj koyunlarında VKS ile doğuran koyun başına düşen kuzu sayısı arasında pozitif yönde önemli bir korelasyon bulunduğu ifade edilmektedir (Uçar ve ark, (2005). Rhind ve ark. (1985), yüksek VKS'li (>4) koyunlarda embriyo kayıplarının arttığını ve üreme performansının azaldığını bildirmişlerdir. Ergin koyunlarda, çok düşük veya çok yüksek VKS, üreme performansinı olumsuz yönde etkileyebilmektedir (Kenyon ve ark., 2004; Maurya ve ark., 2009; Sejian ve ark., 2009; Yllmaz ve ark., 2011).

Araştırma kapsamında değerlendirilen özellikler arası korelasyon katsayıları hesaplanmış ve sonuçlar Çizelge 3'te verilmiştir. CA ile VKS ve SKY; VKS ile DA ve GCAA; DA ile SKA, SKY, GCAA; SKA ile SKY, GCAA arasındaki korelasyonlar önemli bulunmuştur $(\mathrm{P}<0.01$; $\mathrm{P}<0.05)$. Kuzularda GCAA ile SKA arasındaki korelasyon katsayısı beklendiği gibi yüksek ve $\mathrm{r}=+0.877$ 'dir. $\mathrm{Bu}$ çalışmada doğum dönemindeki koyunların VKS ile kuzuların DA ve büyüme hızları arasındaki korelasyon katsaylları pozitif ve önemlidir $(\mathrm{P}<0.05)$. Bu sonuç kuzularda daha yüksek DA ve canlı ağırlık kazancı için anaların kondisyon skorunun gerek gebelik gerekse doğum dönemindeki önemini de ortaya koymaktadir.

Çizelge 3. Koyun ve kuzulara ait incelenen özellikler arasındaki korelasyonlar

\begin{tabular}{llllll}
\hline Özellikler & KCA & VKS & DA & SKA & SKY \\
\hline VKS & $0.440^{* *}$ & & & & \\
DA & 0.050 & $0.301^{* *}$ & & & \\
SKA & 0.164 & 0.162 & $0.378^{* *}$ & & \\
SKY & $0.199^{*}$ & -0.125 & $-0.289^{* *}$ & $0.465^{* *}$ & \\
GCAA & 0.088 & $0.219^{*}$ & $0.425^{* *}$ & $0.877^{* *}$ & 0.025 \\
\hline${ }^{* *} \mathrm{P}<0.01,{ }^{*} \mathrm{P}<0.05$ & & & &
\end{tabular}

VKS: Vücut kondsiyon skoru, DA: Doğum ağırlığı, SKA: Sütten kesim ağırlı̆̆ı, SKY: Sütten kesim yaşı, GCAA: Günlük canlı ağırlık artışı

Araştırmada koyunların kondisyon skorları ile canlı ağırlıkları arasında önemli bir ilişkinin olduğu saptanmıştır. Belirlenen korelasyon $(\mathrm{r}=0.44)$ değeri, koyunların boyut ve iskelet yapisındaki farklllıklara bağlı olarak, Vatankhah ve ark. (2012)'nın LoriBakhtiari koyunlarında bulduğu $(r=0.29)$ değerden yüksek, Kıvırcık koyunu için bildirilen değerden ise ( $r=0.59)$ düşüktür (Yllmaz ve ark., 2011).

Molina ve ark. (1991)'nın Manchega ırkı koyunlarda VKS’nin kuzulama mevsimi ve doğum tipine göre değişimi ve kuzu gelişmesine olan etkilerini inceledikleri araştırmada, tek doğuran koyunlarda kuzulamadaki VKS ile DA, GCAA ve SKA arasındaki korelasyon katsayılarını tekiz kuzularda sirasıyla 0.931, 0.634 ve 0.955 , ikiz kuzularda ise; $0.744,0.467$ ve 0.668 olarak hesaplamişlardır. Kuzulama döneminde ve sütten kesimde VKS'nin, kuzulama mevsimi ve doğum tipine göre değiştiğini belirlemişlerdir $(\mathrm{P}<0.01)$. O'Connor (1996) ise DA ve büyüme oranları ile kuzuların SKA'sı arasında pozitif bir ilişki olduğunu, bu nedenle kuzu DA'sını artırabilen herhangi bir yönetim uygulamasının kuzuların sütten kesime kadar ki gelişmelerini olumlu etkileyeceğini belirtmektedir. Kıvırcık koyunları üzerinde yapılan bir çalışmada ise VKS ve DA arasındaki korelasyon katsayısı bu araştırma sonuçlarından düşük ve $r=0.248$ olarak belirlenmiştir (Ada ve ark., 2004).

Kuzularda DA ve SKY'nin SKA üzerine etkisi önemlidir $(\mathrm{P}<0.01)$. Doğum tipi, cinsiyet, DA ve SKY'yi kullanarak SKA'yı tahmin etmek için kullanılabilecek regresyon eşitliği aşağıdaki gibi tahmin edilmiştir.

$\mathrm{SKA}=-13.19+2.43 \mathrm{DA}+0.326 \mathrm{SKY}+1.343 \mathrm{Tek}$ - 1.343İkiz + 0.656Erkek - 0.656Dişi 
Çizelge 4. Kıvırcık kuzularında doğum ağırlığına ve sütten kesim yaşına göre sütten kesim ağırlığının değişimi

\begin{tabular}{|c|c|c|c|c|c|c|c|c|c|c|c|c|c|c|c|c|c|c|c|c|c|c|}
\hline 90 & 20.8 & 21.3 & 21.8 & 22.2 & 22.7 & 23.2 & 23.7 & 24.2 & 24.7 & 25.2 & 25.6 & 26.1 & 26.6 & 27.1 & 27.6 & 28.1 & 28.6 & 29.0 & 29.5 & 30.0 & 30.5 & 31.0 \\
\hline 88 & 20.1 & 20.6 & 21.1 & 21.6 & 22.1 & 22.6 & 23.1 & 23.5 & 24.0 & 24.5 & 25.0 & 25.5 & 26.0 & 26.5 & 26.9 & 27.4 & 27.9 & 28.4 & 28.9 & 29.4 & 29.9 & 30.3 \\
\hline 86 & 19.5 & 20.0 & 20.5 & 20.9 & 21.4 & 21.9 & 22.4 & 22.9 & 23.4 & 23.9 & 24.3 & 24.8 & 25.3 & 25.8 & 26.3 & 26.8 & 27.3 & 27.7 & 28.2 & 28.7 & 29.2 & 29.7 \\
\hline 84 & 18.8 & 19.3 & 19.8 & 20.3 & 20.8 & 21.3 & 21.7 & 22.2 & 22.7 & 23.2 & 23.7 & 24.2 & 24.7 & 25.1 & 25.6 & 26.1 & 26.6 & 27.1 & 27.6 & 28.1 & 28.6 & 29.0 \\
\hline 82 & 18.2 & 18.7 & 19.2 & 19.6 & 20.1 & 20.6 & 21.1 & 21.6 & 22.1 & 22.6 & 23.0 & 23.5 & 24.0 & 24.5 & 25.0 & 25.5 & 26.0 & 26.4 & 26.9 & 27.4 & 27.9 & 28.4 \\
\hline 80 & 17.5 & 18.0 & 18.5 & 19.0 & 19.5 & 20.0 & 20.4 & 20.9 & 21.4 & 21.9 & 22.4 & 22.9 & 23.4 & 23.8 & 24.3 & 24.8 & 25.3 & 25.8 & 26.3 & 26.8 & 27.2 & 27.7 \\
\hline 78 & 16.9 & 17.4 & 17.8 & 18.3 & 18.8 & 19.3 & 19.8 & 20.3 & 20.8 & 21.2 & 21.7 & 22.2 & 22.7 & 23.2 & 23.7 & 24.2 & 24.7 & 25.1 & 25.6 & 26.1 & 26.6 & 27.1 \\
\hline 76 & 16.2 & 16.7 & 17.2 & 17.7 & 18.2 & 18.7 & 19.1 & 19.6 & 20.1 & 20.6 & 21.1 & 21.6 & 22.1 & 22.5 & 23.0 & 23.5 & 24.0 & 24.5 & 25.0 & 25.5 & 25.9 & 26.4 \\
\hline 74 & 15.6 & 16.1 & 16.5 & 17.0 & 17.5 & 18.0 & 18.5 & 19.0 & 19.5 & 19.9 & 20.4 & 20.9 & 21.4 & 21.9 & 22.4 & 22.9 & 23.3 & 23.8 & 24.3 & 24.8 & 25.3 & 25.8 \\
\hline 72 & 14.9 & 15.4 & 15.9 & 16.4 & 16.9 & 17.3 & 17.8 & 18.3 & 18.8 & 19.3 & 19.8 & 20.3 & 20.8 & 21.2 & 21.7 & 22.2 & 22.7 & 23.2 & 23.7 & 24.2 & 24.6 & 25.1 \\
\hline 70 & 14.3 & 14.8 & 15.2 & 15.7 & 16.2 & 16.7 & 17.2 & 17.7 & 18.2 & 18.6 & 19.1 & 19.6 & 20.1 & 20.6 & 21.1 & 21.6 & 22.0 & 22.5 & 23.0 & 23.5 & 24.0 & 24.5 \\
\hline 66 & 13.0 & 13.4 & 13.9 & 14.4 & 14.9 & 15.4 & 15.9 & 16.4 & 16.9 & 17.3 & 17.8 & 18.3 & 18.8 & 19.3 & 19.8 & 20.3 & 20.7 & 21.2 & 21.7 & 22.2 & 22.7 & 23.2 \\
\hline 64 & 12.3 & 12.8 & 13.3 & 13.8 & 14.3 & 14.7 & 15.2 & 15.7 & 16.2 & 16.7 & 17.2 & 17.7 & 18.1 & 18.6 & 19.1 & 19.6 & 20.1 & 20.6 & 21.1 & 21.5 & 22.0 & 22.5 \\
\hline 62 & 11.7 & 12.1 & 12.6 & 13.1 & 13.6 & 14.1 & 14.6 & 15.1 & 15.5 & 16.0 & 16.5 & 17.0 & 17.5 & 18.0 & 18.5 & 18.9 & 19.4 & 19.9 & 20.4 & 20.9 & 21.4 & 21.9 \\
\hline 60 & 11.0 & 11.5 & 12.0 & 12.5 & 13.0 & 13.4 & 13.9 & 14.4 & 14.9 & 15.4 & 15.9 & 16.4 & 16.8 & 17.3 & 17.8 & 18.3 & 18.8 & 19.3 & 19.8 & 20.2 & 20.7 & 21.2 \\
\hline 58 & 10.4 & 10.8 & 11.3 & 11.8 & 12.3 & 12.8 & 13.3 & 13.8 & 14.2 & 14.7 & 15.2 & 15.7 & 16.2 & 16.7 & 17.2 & 17.6 & 18.1 & 18.6 & 19.1 & 19.6 & 20.1 & 20.6 \\
\hline 56 & 9.7 & 10.2 & 10.7 & 11.2 & 11.6 & 12.1 & 12.6 & 13.1 & 13.6 & 14.1 & 14.6 & 15.0 & 15.5 & 16.0 & 16.5 & 17.0 & 17.5 & 18.0 & 18.5 & 18.9 & 19.4 & 19.9 \\
\hline 54 & 9.1 & 9.5 & 10.0 & 10.5 & 11.0 & 11.5 & 12.0 & 12.5 & 12.9 & 13.4 & 13.9 & 14.4 & 14.9 & 15.4 & 15.9 & 16.3 & 16.8 & 17.3 & 17.8 & 18.3 & 18.8 & 19.3 \\
\hline 52 & 8.4 & 8.9 & 9.4 & 9.9 & 10.3 & 10.8 & 11.3 & 11.8 & 12.3 & 12.8 & 13.3 & 13.7 & 14.2 & 14.7 & 15.2 & 15.7 & 16.2 & 16.7 & 17.1 & 17.6 & 18.1 & 18.6 \\
\hline & 2.2 & 2.4 & 2.6 & 2.8 & 3.0 & 3.2 & 3.4 & 3.6 & 3.8 & 4.0 & 4.2 & 4.4 & 4.6 & 4.8 & 5.0 & 5.2 & 5.4 & 5.6 & 5.8 & 6.0 & 6.2 & 6.4 \\
\hline
\end{tabular}


Doğum tipine ve cinsiyete göre değişmekle birlikte DA'nın $1 \mathrm{~kg}$ artmasına karşılık SKA $2.43 \mathrm{~kg}$, SKY'nin 1 gün uzamasına paralel SKA'nın $0.326 \mathrm{~kg}$ artacağ söylenebilir. Söz konusu regresyon denklemi kullanılarak Kıvırcık kuzularında çeşitli DA ve SKY için tahmin edilen SKA değerleri Çizelge 4'te verilmiştir.

Sezenler ve ark. (2011) tarafından bir birim VKS'nin, koyunların canlı ağırlığında üreme, kuzulama ve sütten kesme dönemlerinde sirasiyla $6.962,6.771$ ve 7.074 kg'a eşdeğer olduğu ve bu değişimlerin önemli bulunduğu belirtmektedirler $(\mathrm{P}<0.01)$. Özder ve ark. (1997), Türkgeldi koyunlarında canlı ağırlık ve kondisyon puanı arasındaki ilişkileri belirlemek amacıyla yaptıkları araştırmada kondisyon puanındaki her bir birimlik değişimin canlı ağırlıkta aşım dönemi için $10.961 \mathrm{~kg}$, kuzulama dönemi için $10.376 \mathrm{~kg}$ ve sütten kesim dönemi içinde $7.310 \mathrm{~kg} \mathrm{~kg}^{\prime} \mathrm{lk}$ bir değişimle sonuçlandığını saptamışlardır. Treacher ve Filo (1995), Ivesi koyunlarında depo yağları, kondisyon skoru ve canlı ağırlık arasındaki ilişkileri belirlemek amacıyla yaptıkları araştırmada, kondisyon puanındaki her birimlik değişimin canlı ağırlıkta 11.8 kg'lık bir değişim meydana getirdiğini belirlemişlerdir.

\section{SONUÇ}

Yerli koyun ırklarının kuzu üretimini arttırmak için uygulanacak beslenme programlarmin belirlenmesi açısından tüm fizyolojik dönemlerde VKS hakkında bilgi sahibi olmak önemlidir. Farklı fizyolojik dönemlerde koyunlarm dengeli bir rasyon ile beslenebilmeleri için VKS kullanılmalıdır. Bununla birlikte ele alınan dönemler için kondisyon skorlamasının, ırka ve bölgeye göre değişebileceği unutulmamalıdır. Bu nedenle, her bir ırk için genel bir standart VKS yerine, farklı fizyolojik dönemler için ayrı ayrı ve yerel olarak belirlenmelidir. Buna ek olarak, irkların VKS'lerini mevcut bölgesel koşullarında karşılaştırmak daha doğru olacaktır. Özellikle koyun yetiştirmede üreme sezonunda, koyunların VKS ile değerlendirilmesi, sinırlı yem kaynaklarının daha etkin kullanımını sağlayabilir ve üretkenliği artırabilir $\mathrm{ki}$ bu da üretimin daha ekonomik bir şekilde gerçekleşmesini sağlayacaktır. $\mathrm{Bu}$ kapsamda koyun yetiştiriciliğinde verimliliği attırmak için yıllık mera mevsimi ve mera koşullarına göre dikkatli bir planlama yapılmalı ve koyunlar fizyolojik dönemlerine uygun VKS değerlerine sahip olmalıdir.

\section{KAYNAKLAR}

Abdel-Mageed I 2009. Body Condition Scoring of Local Ossimi Ewes Mating and its Impact on Fertility and Prolificacy. Egyptian Journal of Sheep and Goat Sciences, 4: 37-44.
Ada M, Ceyhan A, Sezenler T, Özder M, Köycü E 2004. Farklı Kondüsyon Puanına Sahip Kıvırcık Koyunlarında Aşım Dönemi Ek Yemlemenin (Flushing) Kuzu Verimi Üzerine Etkileri. Çukurova Üniversitesi Ziraat Fakültesi Dergisi, 19(1): 89-96.

Aktaş AH, Doğan S 2014. Effect of Live Weight and Age of Akkaraman Ewes at Mating on Multiple Birth Rate, Growth Traits, and Survival Rate of Lambs. Turkish Journal of Veterinary and Animal Sciences, 38: $176-182$.

Aliyari D, Moeini MM, Shahir MH, Sirjani MA 2012. Effect of Body Condition Score Live Weight and Age on Reproductive Performance of Afshari Ewes. Asian Journal of Animal and Veterinary Advances, 7: 904909.

Al-Sabbagh T 2009. Colotral Immunoglobulin as Affected by Nutritional Status in Border Leicester Merino Ewes Deliver at Kuwait. Global Veterinaria, 3: 281285.

Al-Sabbagh TA, Swanson LV, Thompson JM 1995. The Effect of Body Condition at Lambing on Colostral İmmunoglobulin $\mathrm{G}$ Concentration and Lamb Performance. Journal of Animal Science, 73: 28602864.

Anonim, 2013. Ewe Body Conditıon Condition Scorıng Scoring (Bcs) Handbook. Beeflamb, www.beeflambnz.com (15.04.2017).

Atti N, Theriez M, Abdennebi L 2001. Relationship Between Ewe Body Condition at Mating and Reproductive Performance in the Fat-Tailed Barbarine Breed. Animal Research, 50:135-144.

Borg RC, Notter DR, Kott RW 2009. Phenotypic and Genetic Associations between Lamb Growth Traits and Adult Ewe Body Weights in Western Range Sheep. Journal of Animal Science, 87: 3506-3514.

Corner-Thomas RA, Hickson RE, Morris ST, Kenyon PR 2014. The Influences of Live Weight and Body Condition Score of Ewe Lambs From Breeding to Lambing on the Live Weight of Their Singleton Lambs to Weaning. Small Ruminant Research, 119: 16-21.

Corner-Thomas RA, Ridler AL, Morris ST, Kenyon PR 2015. Ewe Lamb Live Weight and Body Condition Scores Affect Reproductive Rates in Commercial Flocks. New Zealand Journal of Agricultural Research, 58(1): 26-34.

Gibb MJ, Treacher TT 1980. The Effect of Ewe Body Condition at Lambing on the Performance of Ewes and Their Lambs at Pasture. Journal of Agricultural Science, 95: 631-640.

Gibb MJ, Treacher TT 1982. The Effect of Body Condition and Nutrition during Late Pregnancy on the Performance of Grazing Ewes during Lactation. Animal Production, 34: 123-129.

Gordon IR 1997. Controlled Reproduction in Sheep and Goats. CAB International, Wallingford, Oxon, UK, 450 p. 
Hossamo HE, Owen JB, Farid MFA 1986. Body Condition Score and Production in Fat-Tailed Awassi Sheep under Range Conditions. Research and Development in Agriculture, 3: 99-104.

Idris AO, Elemam MB, Kijora C, El-Hag FM, Salih AM 2011. Effect of Dietary Supplementation, Sex and Birth Type on Body Weight of Desert Ewes and Their Lambs' Growth Performance in Semi Arid Area of Kordofan State, Sudan, Livestock Research for Rural Development, 23: 1-9.

Jalilian MT, Moeini MM 2012. The Effect of Body Condition Score of Morghoz Goats on Reproductive Parameters Were Studied. 5th Congress of Animal Science Association, Isfahan University, 1-3 Sep. (Abstract book).

Jalilian MT, Moeini MM 2013 The Effect of Body Condition Score and Body Weight of Sanjabi Ewes on Immune System, Productive and Reproductive Performance. Acta Agriculturae Slovenica, 102: 99106.

Karakus F, Atmaca M 2016. The Effect of Ewe Body Condition at Lambing on Growth of Lambs and Colostral Specific Gravity. Archives Animal Breeding, 59: 107-112.

Kenyon PR, Morel PCH, Morris ST 2004. The Effect of Individual LiveweightLive weight and Condition Scores of Ewes at Mating on Reproductive and Scanning Performance. New Zealand Veterinary Journal, 52: 230-235.

Kenyon PR, Morris ST, Burnham DL, West DM 2008. Effect of Nutrition during Pregnancy on Hogget Pregnancy Outcome and Birthweight and LiveweightLive weight of Lambs. New Zealand Journal of Agricultural Research, 51: 77-83.

Kenyon PR, Morris ST, Hickson RE, Back PJ, Ridler AL, Stafford KJ, West DM 2013. The Effects of Body Condition Score and Nutrition of Triplet-Bearing Ewes in Late Pregnancy. Small Ruminant Research, 113: 154-161.

Kenyon PR, Morris ST, Stafford KJ, West DM 2011. The Effect of Ewe Body Condition and Nutrition in Late Pregnancy on the Performance of Triplet bearing Ewes and Their Progeny. Animal Production Science, 51: $557-564$.

Khan K 1993. Effects of Body Condition and PreLambing Supplementation on Ewe Productivity. MS Thesis, Oregon State University, Oregon, USA, 102p.

Litherland AJ, Lambert MG, McLaren PN 1999. Effects of Herbage Mass and Ewe Condition Score at Lambing on Lamb Survival and Live weight Gain. Proceedings of the New Zealand Society of Animal Production, 59: 104-107.

Lopez F, Espejo M, Villar A 1995. Evolution of Ewe Body Condition and the Production of Lamb and Milk in Different Productive Strategies. Zaragosa: CIHEAMIAMZ, p.53-58.

Mathias-Davis HC, Shackell GH, Greer GJ, Bryant AI. Everett-Hincks JM 2013. Ewe Body Condition Score and The Effect on Lamb Growth Rate. Proceedings of the New Zealand Society of Animal Production. 73: 131-135.

Maurya VP, Kumar S, Kumar D, Gulyani R, Joshi A, Naqvi SMK, Arora AL, Singh VK 2009. Effect of Body Condition Score on Reproductive Performance of Chokla Ewes. Indian Journal of Animal Sciences, 79: 1136-1138.

McCall DG, Smeaton DC, Wadam TK, Gibbison ML, Hockey HUP 1986. Lambing Date, Ewe Live weight and Pasture Mass Effects on Ewe and Lamb Performance during Lactation. Proceedings of the New Zealand Society of Animal Production, 46: 12932 .

Minitab 2010. Minitab Inc. MINITAB: Minitab for Windows Version Release 17. State College, PA, USA: Minitab Inc.

Molina A, Gallego L, Perez JI, Bernabeu R 1991. Growth of Manchega Lambs in Relation to Body Condition of Dam, Season of Birth, Type of Birth and Sex. Avances en Alimentaciony Mejora Animal, 31: 198-205.

Morel PCH, Kenyon PR 2006. Sensitivity Analysis of Weaner Lamb Production in New Zealand. Proceedings of the New Zealand Society of Animal Production, 66: 377-381.

Morris ST, Kenyon PR, West DM 2005. Effect of Hogget Nutrition In pregnancy on Lamb Birth Weight and Survival to Weaning. New Zealand Journal of Agricultural Research, 48: 165-175.

Mulvaney FJ, Morris ST, Kenyon PR, Morel PCH, West DM 2010.Effect of Nutrition Pre-breeding and during Pregnancy on Breeding Performance of Ewe Lambs. Animal Production Science, 50: 953-960.

O'Connor CEO 1996. Ewe Maternal Behaviour Score and Lamb Growth: Ten Years on. Proceedings of the New Zealand Society of Animal Production, 56: 107-109.

Özder M, Arık IZ, Yurtman IY, Ozduven ML 1997. Türkgeldi Koyunlarında Kondüsyon Puanı, Yaş ve Canlı Ağırlığın Bazı Performans Özellikleri Üzerine Etkileri. Akdeniz Üniversitesi Ziraat Fakültesi Dergisi, 10: 119-128.

Rhind SM, Leslie LD, Gunn RG, Doney JM 1985. Plasma FSH, LH, Prolactin and Progesterone Profiles of Cheviot Ewes with Different Levels of Intake Before and After Mating, and Associated Effects on Reproductive Performance. Animal Reproduction Science, 8: 301-313.

Rhind SM, Rae MT, Brooks AN 2001. Effects of Nutrition and Environmental Factors on the Fetal Programming of the Reproductive Axis. Reproduction, 122: $205-214$.

Russel AJF, Doney JM, Gunn RG 1969. Subjective Assessment of Body Fat in Live Sheep. Journal of Agricultural Science, 72: 451-454.

Russel AJF, Foot JZ, White IR, Davies GJ 1981. The Effect of Weight at Mating and of Nutrition during Mid-pregnancy on the Birthweight of Lambs from 
Primiparous Ewes. Journal of Agricultural Science, 97: 723-729.

Samardzija M, Vince S, Duricic D 2013. Association of Parity, Fecundity and Body Condition Score with Blood Serum Concentration of Some Metabolites during Pre and Post Parturient Period in German Improved Fawn Goats. Veterinarski Arhiv, 83(5): 469477.

Sanson DW, West TR, Tatman WR, Riley ML, Judkins MB, Moss GE 1993. Relationship of Body Composition of Mature Ewes with Condition Score and Body Weight. Journal of Animal Science, 71: 1112-1126.

Sarı M, Önk K, Aksoy AR, Tilki M 2013. Tuj Koyunlarında Doğum Kondisyon Puanının Kuzuların Büyüme Özellikleri ve Yaşama Gücüne Etkisi. Fırat Üniversitesi Sağlık Bilimleri Veteriner Dergisi, 27: 149-154.

Scaramuzzi RJ, Campbell BK, Downing JA, Kendall NR, Khalid M, Munoz-Gutierrez M, Somchit A 2006. A Review of the Effects of Supplementary Nutrition in the Ewe on the Concentrations of Reproductive and Metabolic Hormones and the Mechanisms that Regulate Folliculogenesis and Ovulation Rate. Reproduction Nutrition Development, 46: 339-354.

Schreurs NM, Kenyon PR, Morel PCH, West DM, Morris ST 2010. Response of Additional Ewe Live weight during Gestation on the Birthweight and Weaning Weight of Offspring and Weight of te Ewe Lamb at Weaning. Animal Production Science, 50: 528-532.

Sejian V, Maurya VP, Naqvi SMK, Kumar D, Joshi A 2009. Effect of Induced Body Condition Score Differences on Physiological Response, Productive and Reproductive Performance of Malpura Ewes Kept in a Hot, Semi-Arid Environment. Journal of Animal Physiological and Animal Nutrition, 94: 154-161.

Sejian V, Maurya VP, Naqvi SMK, Kumar D, Joshi A 2010. Effect of Induced Body Condition Score Differences on Physiological Response, Productive and Reproductive Performance of Malpura Ewes Kept in a Hot, Semiarid Environment. Journal of Animal Physiology and Animal Nutrition, 94: 154-161.

Sejian V, Maurya VP, Prince LLL, Kumar D, Naqvi SMK 2015. Effect of Body Condition Score on the Allometric Measurements and Reproductive Performance of Garole x Malpura Ewes under Hot Semi-Arid Environment. Journal of Dairy, Veterinary \& Animal Research, 2(6): 1-4.

Sezenler T, Köycü E, Özder M 2008. Karacabey Merinosu Koyunlarda Doğum Kondüsyon Puanının Kuzuların Gelişimi Üzerine Etkileri. Tekirdağ Ziraat Fakültesi Dergisi, 5: 45-53.

Sezenler T, Yildirir M, Ceyhan A, Yüksel MA; Önal AR, Özder M 2011. The Effects of Body Condition Score and Age of Ewes on the Reproductive Performance in Kivircik, Sakiz and Gokceada Sheep. Journal of Animal Science Advances, 1: 94-99.
Smeaton DC, Webby RW, Tarbotton IS 1999. Nutritional Effects, in Early Pregnancy, on Lamb Production of Finnish Landrace $x$ Romney Ewes. Proceedings of the New Zealand Society of Animal Production, 59: 108110.

Thompson J, Meyer H 1994. Body Condition Scoring of Sheep. Oregan State University Extension Servise.

Thompson JM, Meyer H 2006. Body Condition Scoring of Sheep. Proc. 52nd Bien. Spooner Sheep D. 28p.

Treacher T, Filo S 1995. Relationships between Fat Depots and Body Condition Score or Live Weight in Awassi Ewes. Zaragosa: CIHEAM - IAMZ, 13-17p.

Ucar O, Kaya M, Yildiz S, Onder F, Cenesiz M, Uzun M 2005. Effect of progestagen/PMSG treatment for oestrus synchronization of Tuj ewes to be bred after the natural breeding season, Acta Veterinaria Brno, 74: 385-393.

van Burgel AJ, Oldham CM, Behrendt R, Curnow M, Gordon DJ, Thompson AN 2011. The Merit of Condition Score and Fat Scores as Alternatives to Live Weight for Managing the Nutrition of Ewes. Animal Production Science, 51: 834-841.

Vatankhah M, Talebi MA, Zamani F 2012. Relationship between Ewe Body Condition Score (BCS) at Mating and Reproductive and Productive Traits in LoriBakhtiari Sheep. Small Ruminant Research, 106: 105-109.

Wallace JM 2000. Nutrient Partitioning during Pregnancy: Adverse Gestational Outcome in Overnourished Adolescent Dams. Proceedings of the Nutrition Society, 59: 107-117.

Wallace JM, Milne JS, Matsuzaki M, Aitken RP 2008. Serial Mea-surement of Uterine Blood Flow from Mid to Late Gestation in Growthrestricted Pregnancies Induced by Overnourishing Adolescent Sheepdams. Placenta, 29: 718-724.

Wilson JW, English PR, Macdonald DC, Bampton PR, Warren M, Birnie M, MacPherson O 1985. Factors Influencing Lamb Growth Rate in An Upland Flock of Blackface Ewes Producing Greyface Lambs. Animal Production, 40: 563.

Yilmaz M, Altin T, Karaca O, Cemal I, Bardakcioglu HE, Yilmaz O, Taskın T 2011. Effect of Body Condition ScoteScore at Mating on the Reproductive Performance of Kivircik Sheep Under under an Extensive Production System. Tropical Animal Health Production, 43: 1555-1560.

Young JM, Thompson AN, Kennedy AJ 2010. Bioeconomic Modelling to Identify the Relative Importance of A Range of Critical Control Points for Prime Lamb Production Systems in South-West Victoria. Animal Production Science, 50: 748-756. 